\title{
Control of Linear Switched Reluctance Motor For biomedical application
}

\author{
ZAAFRANE Wajdi, MAHMOUD Imed, FATHALAH Mourad, REHAOULIA Habib \\ Unit Signal, Image and Intelligent Control of Industrial Systems (SICISI), University of Tunis, Tunisia. \\ High school of Sciences and Technology of Tunis (ESSTT), 5 av. Taha Hussein BP 56 - 1008 Tunis) \\ wajdi.zaafrane@gmail.com
}

\begin{abstract}
The work developed in this paper deals with control of a linear switched reluctance motor (LSRM). The studied actuator is used to motorize a syringe pump in biomedical systems. A model of the actuator is performed neglecting magnetic saturation. Different control and command modes using standard controllers are detailed and tested in this paper. In order to make a constant flow of the liquid in the syringe pump, this paper reports a study of sensor less force and closed loop control of the LSRM with a classical PID and hysteresis controller.
\end{abstract}

Keywords-Linear switched reluctance motor; syringe pump; stepper motor control; linear actuator; closed loop control; sensor less control

\section{INTRODUCTION}

Linear motors are now widely used in many industrial applications especially in high dynamic machinery production (machine tools, robots, etc.) they are strong candidates for both low speed and high speed mass transit applications. [3] [6].

In a context where performance and cost issues are vital, it naturally follows that linear motors must be used to their maximum performances in terms of positioning quality and thrust. Such this motors have the advantage of not having transmission systems to product a linear movement. Consequently, it will lead to decrease friction problems and to increase performances which allows pushing the mechanical limits in terms of acceleration and speed [6][4] .

Also, a linear switched reluctance motor (LSRM) is an electromechanical actuator that can be used as a positioning device because of its simplicity of manufacturing and its reduced cost [5] [6].

In recent years, control of this actuator is attracting much attention due to the development of control theory and computer hardware.

This type of motor is characterized by a particular structure similar to that of the rotary stepper motor and it is widely used in open loop control. During the 1970s the closed loop control was introduced in stepper motor in order to increase the positioning accuracy and to reduce their sensitivity to disturbances load [1], [2].

Today, thanks to advances in power electronics and in computer science applications, LSRMs are used in closed loop control especially in robotics and in biomedical applications. Therefore, sensors which are necessary to measure main parameters (force, current position ...) are expensive and sometimes difficult to get into certain application.

The objective of this paper is double. The first part consists of modeling the LSRM which is difficult to control because the undesired oscillations in force and position. The second part concerns the control of the actuator for motorization of the pump syringe. The main contribution of this paper is the development of a control algorithm optimized for closed-loop control of the position and the force with classical PID controller and hysteresis current controller without force sensor.

\section{PUMP SYRINGE}

The syringe pump is an important biomedical service in hospitals where the patient is subjected to treatment requiring infusions at high concentrations over a long period with adjustable flow rate and precision [7] [8].

The motorization of these biomedical systems is generally provided by a rotating stepping motor associated to a gear unit. This latter connecting the syringe to the rotating motor, is bulky, expensive and frequently source of failure [8].

In order to improve the compatibility of the system and to increase the accuracy of the mechanical transmission between the actuator and the syringe piston, the LRSM with suitable position control is selected [7].

Figure (1) shows the architecture of the full biomedical system where the motorization is provide by a LSRM which increases the system accuracy and reduces its maintenance.

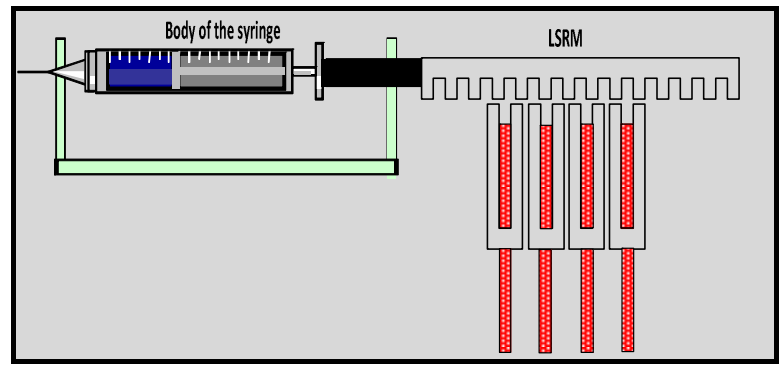

Fig. 1: Architecture of the syringe pump powered by LSRM. 
The actuator proposed is a linear switched reluctance motor composed by a toothed sliding part on a rail and a plurality of stator modules regularly distributed, Figure (2).

The stator windings are laminated with copper and concentrated around the cylinder heads of the stator [7]. They are excited by DC currents.

The non-magnetic separations between the different modules impose a regular shift. If teeth of an active module are aligned with teeth of the mover, the other stator modules must be unaligned in order to create a translation force. Notice that the mover length of the actuator is $10 \mathrm{~cm}$ with a tooth pitch of $6 \mathrm{~mm}$.

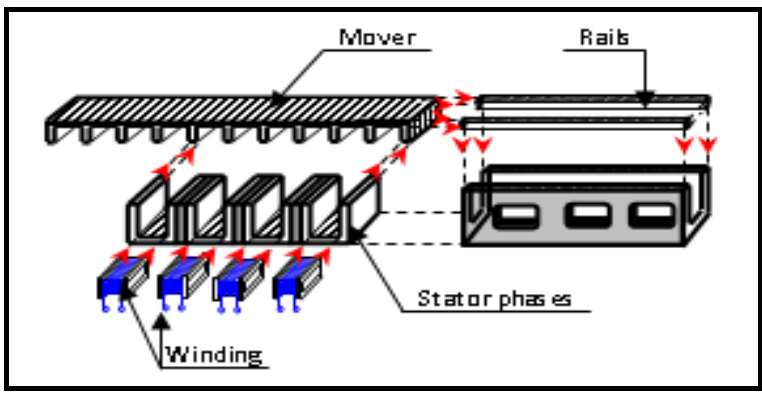

Fig. 2: structure of LSRM [7]

\section{MODELING OF LSRM}

The LSRM has a highly nonlinear characteristic due to its nonlinear flux behavior [13]. In order to simplify equations, the modeling is performed without taking into account magnetic saturation, phases are considered identical and end effect is neglected [13].

Consequently, the fundamental electrical and mechanical equations of an LSRM are, [10] [11] [12]:

$$
\begin{aligned}
& u_{A}=R i_{A}+L_{0} \frac{d i_{A}}{d t}+L_{1} \cos \left(\frac{2 \pi x}{\lambda}\right) \frac{d i_{A}}{d t}+ \\
& \frac{2 \pi}{\lambda} L_{1} \sin \left(\frac{2 \pi x}{\lambda}\right) v i_{A} \\
& u_{B}=R i_{B}+L_{0} \frac{d i_{B}}{d t}+L_{1} \cos \left(\frac{2 \pi x}{\lambda}-\frac{\pi}{2}\right) \frac{d i_{B}}{d t}+ \\
& \frac{2 \pi}{\lambda} L_{1} \sin \left(\frac{2 \pi x}{\lambda}-\frac{\pi}{2}\right) v i_{B} \\
& u_{C}=R i_{C}+L_{0} \frac{d i_{C}}{d t}+L_{1} \cos \left(\frac{2 \pi x}{\lambda}-\pi\right) \frac{d i_{C}}{d t}+ \\
& \frac{2 \pi}{\lambda} L_{1} \sin \left(\frac{2 \pi x}{\lambda}-\pi\right) v i_{C}
\end{aligned}
$$

$$
\begin{gathered}
u_{D}=R i_{D}+L_{0} \frac{d i_{D}}{d t}+L_{1} \cos \left(\frac{2 \pi x}{\lambda}-\frac{3 \pi}{2}\right) \frac{d i_{D}}{d t}+ \\
\frac{2 \pi}{\lambda} L_{1} \sin \left(\frac{2 \pi x}{\lambda}-\frac{3 \pi}{2}\right) v i_{D} \\
\frac{d v}{d t}=-\frac{\pi L_{1}}{m \lambda}\left[i_{A}^{2} \sin \left(\frac{2 \pi}{\lambda} x\right)+i_{B}^{2} \sin \left(\frac{2 \pi}{\lambda} x-\frac{\pi}{2}\right)+\right. \\
\left.-\frac{\xi}{m} v-\frac{F c}{m}-\frac{F 0}{m} \sin \left(\frac{2 \pi x}{\lambda}-\pi\right)+i_{D}^{2} \sin \left(\frac{2 \pi}{\lambda} x-\frac{3 \pi}{2}\right)\right]
\end{gathered}
$$

Where $u$ and $i$ designate voltage and current of phases A,B,C and D, $x$ the displacement, $\lambda$ the tooth pitch, $L_{1}$ and $L_{2}$ the minimum and the maximum inductance, $v$ the speed, $F_{C}$ the load force, $m$ and $\xi$ the mass and friction.

Electrical parameters obtained by the finite element analysis FEA 2D are [7]:

$$
\begin{gathered}
u=18 \mathrm{~V}, L 0=225 \mathrm{mH}, L 1=50 \mathrm{mH}, R=18 \Omega, \\
m=5 \mathrm{Kg}, \lambda=6 \mathrm{~mm} \xi=65 \mathrm{Nm} / \mathrm{s}, F_{0}=0.2 \mathrm{~N}
\end{gathered}
$$

To test the developed models and to verify the effectiveness of various applied controls, MATLAB/ SIMULINK was used as a simulation tool.

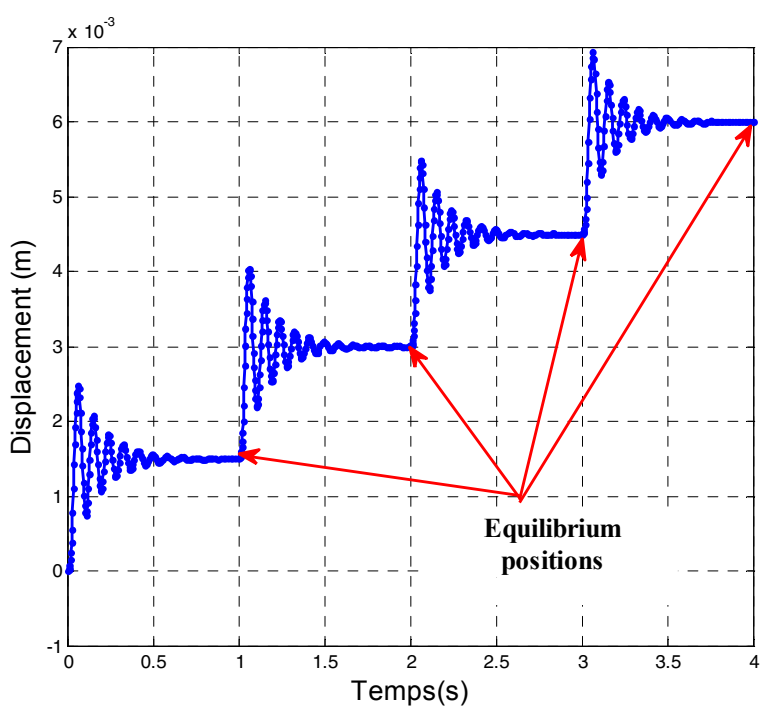

Fig.3: Displacement of the mover as function of time for 4 steps. 


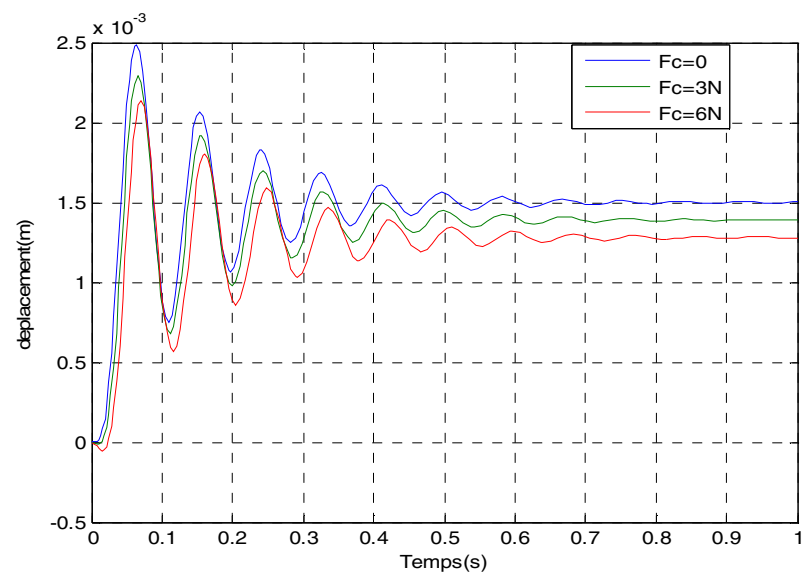

Fig. 4: displacements of the mover for different loads force.

Figure (3) illustrates the operating cycle for 4 steps, where it is shown that the displacement is accompanied by strong oscillations and large overruns. These phenomena affect the position accuracy and may cause loss of synchronization at high speed. To overcome such problems, improvements can be achieved by control techniques in open or closed loop.

\section{$I V . \quad$ LSRM CONTROL IN OPEN-LOOP}

The open-loop control have the merit of simplicity and consequent low cost, its consists to supplying the motor phases in a fixed order according to the direction, so there is no return and no regulation possible and there is no guarantee that the actuator has responded to the command.

This control mode can be positioned with great passing and a strong oscillation as shown in figure (4).

When a load force is applied, the equilibrium position of the LSRM and the force are affected by an error due to the load force which opposes the motion of mover, figure (5) [9].

\section{III.1. Solving the problem positioning with load force}

To solve the problem of error in load mod, we will exploit the evolution curve of force versus time shown in figure (5).

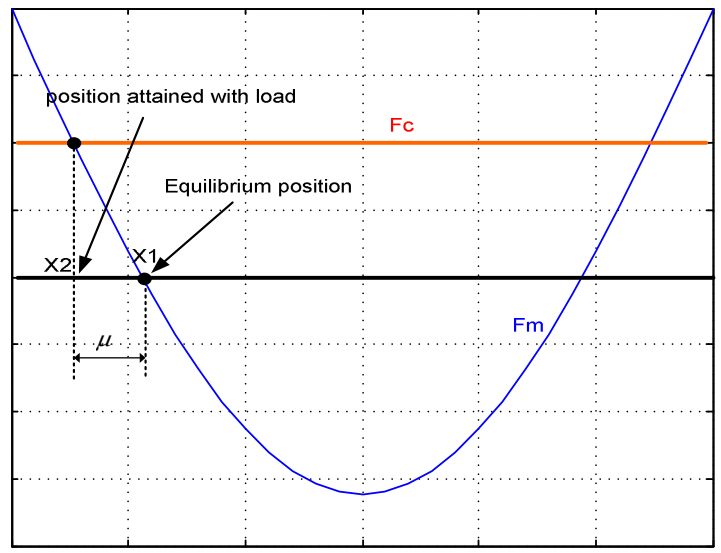

Fig. 5: Positioning difference due to the charge load $\mu$ is the position deviation due to the loading force expressed by equation (7) [9].

$$
\mu=\frac{\lambda}{2 \pi} \arcsin \left(\frac{F_{C}}{F_{M}}\right)
$$

With $F_{M}=\frac{\pi L_{1} i_{B}^{2}}{\lambda}$ is the maximum force developed by the LSRM.

To solve the problem of positioning with loads, the solution is that in the presence of load characterized by the resistive force $(\mathrm{Fc})$. The equilibrium position is attained when the thrust force which is generated by the motor for simultaneous excitation of two phases, equalizes that of the load: $F_{m}=F$, [12].

In the case of phase $\mathrm{B}$ and $\mathrm{C}$, the force generated is:

$$
\begin{aligned}
& F_{m}=-\frac{\pi L 1}{\lambda}\left[i_{B}^{2} \sin \left(\frac{2 \pi}{\lambda}-\frac{\pi}{2}\right)+i_{C}^{2} \sin \left(\frac{2 \pi}{\lambda}-\pi\right)\right] \\
& I_{B}=\sqrt{\frac{-\frac{F c}{F_{M}}+\sin \left(\frac{2 \pi x_{e}}{\lambda}\right)}{\sin \left(\frac{2 \pi x_{e}}{\lambda}\right)-\cos \left(\frac{2 \pi x_{e}}{\lambda}\right)}} I n \\
& I_{C}=\sqrt{\frac{\frac{F c}{F_{M}}+\sin \left(\frac{2 \pi x_{e}}{\lambda}\right)}{\sin \left(\frac{2 \pi x_{e}}{\lambda}\right)-\cos \left(\frac{2 \pi x_{e}}{\lambda}\right)}} I n
\end{aligned}
$$

$$
I_{B}^{2}+I_{C}^{2}=I_{n}^{2}
$$

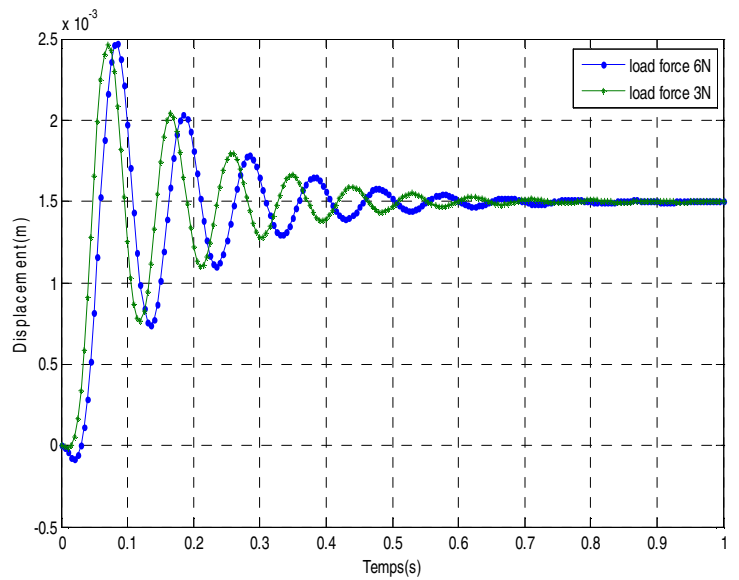

Fig. 6: Movement of the mobile as a function of time to $3 \mathrm{~N}$ and $6 \mathrm{~N}$ In the case of phase $B$ and $C$ 


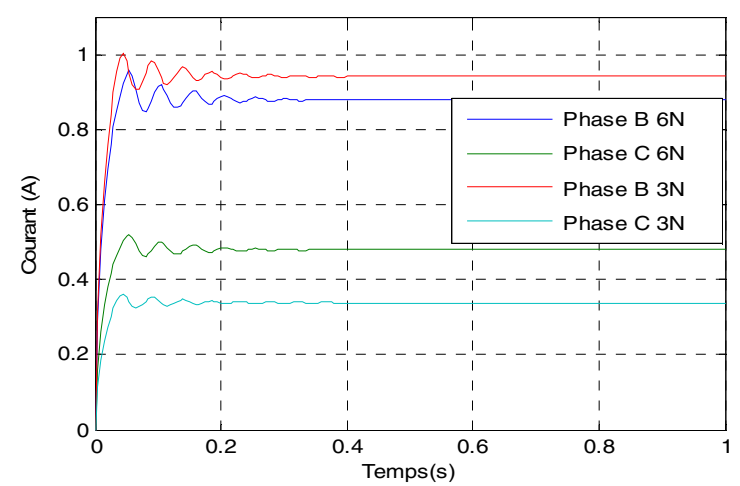

Fig. 7: Supply current for phases to $3 N$ and $6 N$

Figure (6) illustrate the displacement of the mover when it is shown that the mobile reach its equilibrium position without error. With this method and by the modulation of phase currents with the equations (9) we can eliminate the error in load mode with any value of load force but without damping the oscillations.

\section{III.2. Damping the oscillations of movement (Bang-Bang control)}

Bang-bang control is a command used to eliminate oscillations observed in the evolution of the motor position. The principle of this method is the use of two phases to dampen these oscillations [9] [11].

Figure (8) explains the principle of the command, where the phase $B$ is excited until the time $t 1$. At $t 1$, the system switches between the two phases $\mathrm{B}$ and $\mathrm{A}$. the excitation of the coil $\mathrm{B}$ enables the eliminate the energy developed by the phase A. Phase B is excited again and at $\mathrm{t} 2$, phase $\mathrm{A}$ is turned off to keep the final equilibrium position. The braking removes all oscillations and mobile attained its equilibrium position without oscillations. [9].

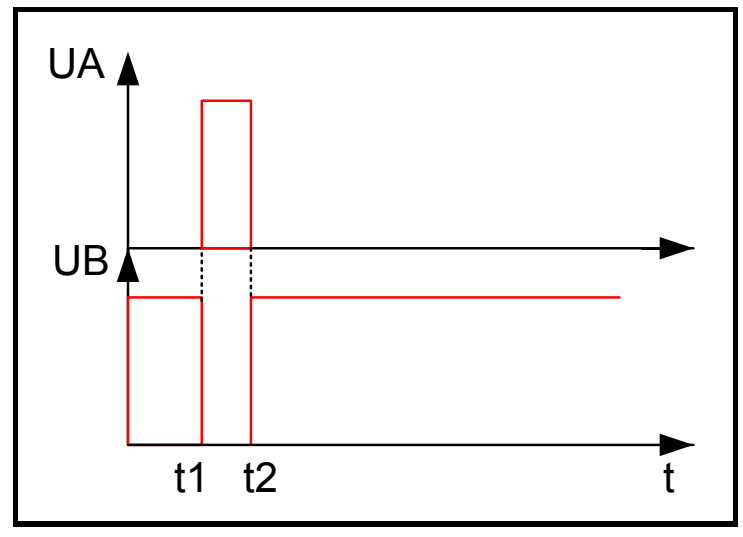

Fig.8: Principle of Bang-Bang control

The determination of $\mathrm{t} 1$ and $\mathrm{t} 2$ is strongly linked to various electrical and mechanical stepper motor parameters [12].

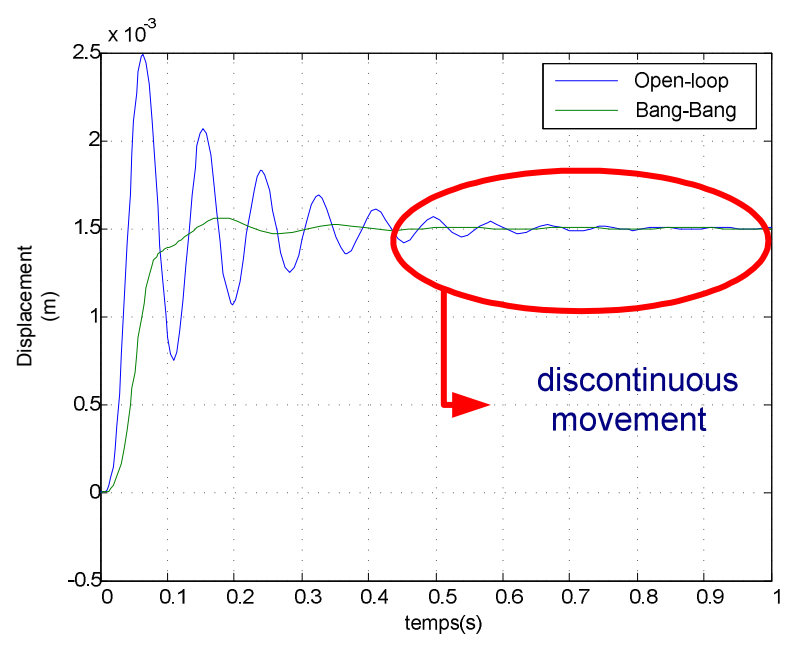

Figure 9: Evolution of the position with Bang-Bang correction

Figure (9) shown the evolution of position of the motor when the phase $\mathrm{A}$ is considered as a braking phase. We can see that the Bang-Bang control allowed minimizing overshoot and damping the oscillations.

The major disadvantage of this technique is that its switching moments control are strongly related to electrical and mechanical actuator parameters so any change requires dynamic adjustment of the switching times [9][11].

The two correction methods (bang-bang and correction in load) eliminate the oscillations and the positioning error in load mod. However, the translation of the mobile is governed by a discontinuous incremental movement accompanied by stopping zones.

The motorization of the syringe pump requires a continuous movement to have a constant flow which leads to the closed loop control.

\section{CLOSED LOOP CONTROL OF LSRM}

In the strategies of stepper motors control in a closed loop mod, the mobile position is detected and fed back into the control unit. Consequently, we can move from a step command to another only when the actuator responded satisfactorily to the previous command and so there is no possibility of losing synchronism [14]. The position sensor is used in two roles:

-Detection of equilibrium positions: the detection of equilibrium is very important to generate the next step command so follow the excitation sequence without missing excited phases (for operation at high speed)

-Detection of the position of the mobile: knowledge of the position of the mobile throughout its travel allows us to work in closed loop. So correction of the position using controllers solves the problems of overshoot and oscillations.

Figure (10) shows the general architecture of control. 


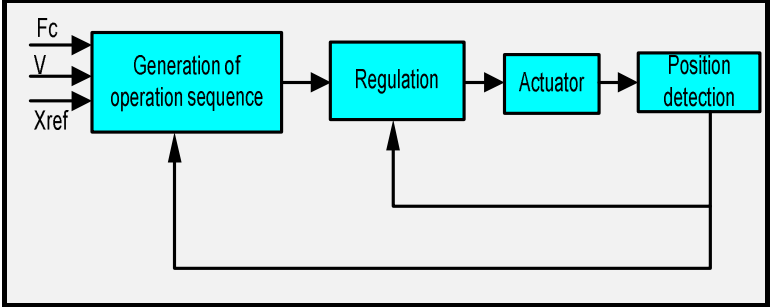

Fig.10: General architecture of closed loop control.

Initially, the system is stopped and the target position is loaded into the control unit, which in turn passes immediately to step command sequence generator phase. Therefore, there is a change in the excitation and motor begins accelerating at a rhythm dictated by the load parameters. The movement of the mobile is regulated throughout the step to dampen oscillations and eliminate overshoot [14].

As the first step has been completed the position detector generates a pulse which is sent to the control unit. That unit contains then the position of the load relative to the target.

The proposed architecture of the closed loop control is detailed in figure (11).

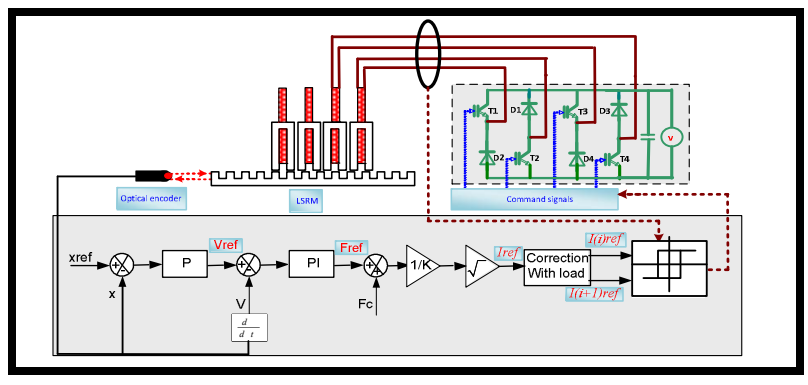

Fig. 11: General architecture of the proposed control.

The general architecture of the control shown in figure (11) is based on the use of conventional PID controllers, a hysteresis current regulator, a position sensor and current sensors [15].

The transfer equations are developed from the mechanical equation (eq.11), where we consider initially the load force equal to zero $(\mathrm{Fc}=0)$ and the mover is in advance movement so $\operatorname{sign}(\mathrm{V})>0$.

$m \frac{d^{2} x}{d^{2} t}=F_{m}-\xi \frac{d x}{d t}$

The transfer function between the position (x) and force (Fm) is given by [14]

$$
\begin{aligned}
& m s V(s)+\xi V(s)=F_{m}(s) \\
& m s^{2} x(s)+\xi s x(s)=F_{m}(s)
\end{aligned}
$$

$$
\begin{aligned}
& V=\frac{d V}{d t} \\
& G(s)=\frac{V(s)}{F_{m}(s)}=\frac{1}{m s+\xi}
\end{aligned}
$$

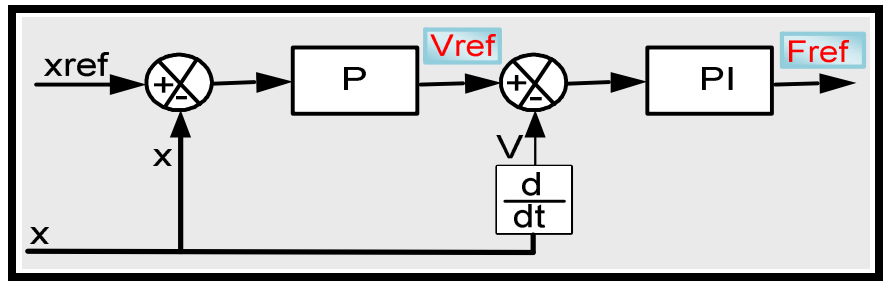

Fig.12: Loop of speed control and position control.

The reference position is compared with the real position of the mover then adjusts with a proportional controller which gives us the reference speed as a picture. The loop of speed control with a PI controller gives the reference force [15]. The force developed by a phase is expressed by [14]

$F_{m}=-i_{A}^{2} L_{1} \frac{\pi}{\lambda} \sin \left(\frac{2 \pi}{\lambda} x\right)$

The displacement to a step is given by: $x=\frac{\lambda}{4}+\Delta x$

$\sin \left(\frac{2 \pi}{\lambda} x\right)=\sin \left(\frac{2 \pi}{\lambda}\left(\frac{\lambda}{4}+\Delta x\right)\right)=\sin \left(\frac{\pi}{2}+\frac{2 \pi}{\lambda} \Delta x\right)$

$=\cos \left(\frac{2 \pi}{\lambda} \Delta x\right)$

$\Delta x$ is small so $\cos \left(\frac{2 \pi}{\lambda} \Delta x\right) \simeq 1$

$F_{m}=K i^{2}$

With $K=L_{1} \frac{\pi}{\lambda}$

The control loop of the force is given by Figure 13

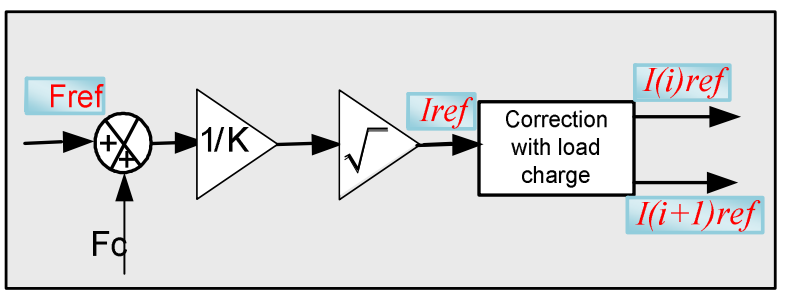

Fig 13: Force control loop 
The regulation of the force developed by the actuator is a very important stage in the system operation. If the force is more stable the flow is more constant.

The use of a control loop with conventional PID regulators requires the use of the force sensor which is difficult to insert in our application. The idea of using the error correction method already studied in the section of open loop control (section III.1) is simpler and allows us to overcome the force sensor problems.

The reference currents generated are introduced into a hysteresis current controller to generate command signal, figure.14.

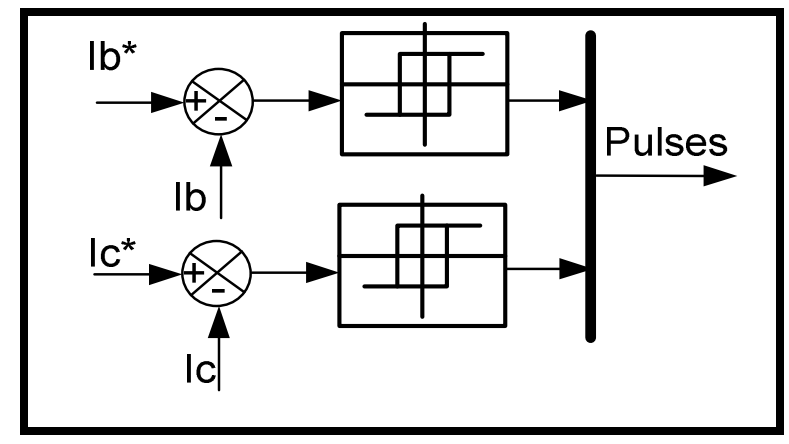

Fig. 14: Hysteresis controller for generating command signals.

Hysteresis controllers are built with Simulink blocks. The currents of the four phases are provided by measure and compared with the reference current. The error of the current then passes through a hysteresis controller to produce the pulses of the control circuit power.

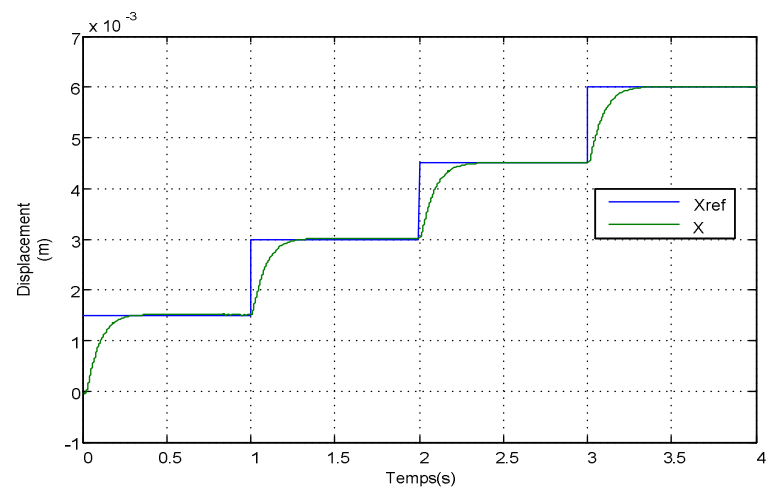

Fig. 15 : Simulation results for classical incrementally functioning $(\mathrm{Fc}=6 \mathrm{~N})$.

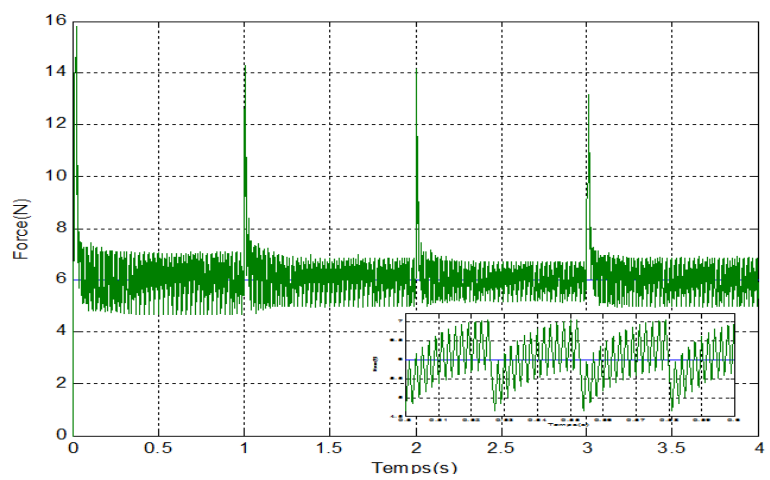

Fig.16: Force developed $\left(F_{c}=6 N\right)$.

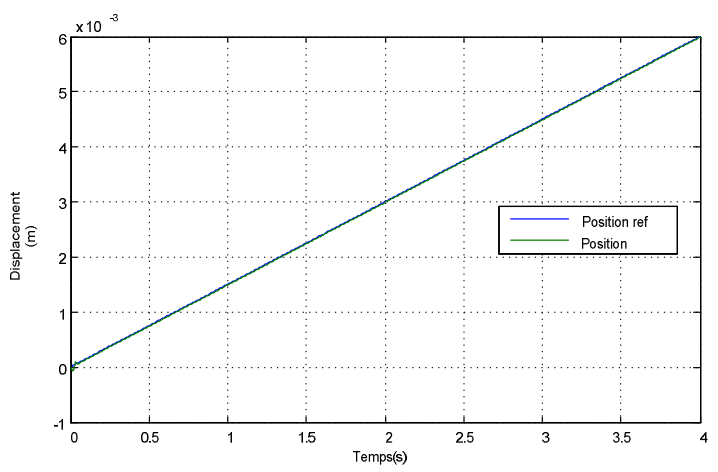

Fig.17: Simulation result for linear displacement.

The evolution of the position for incremental motion (figure.15) and the continuous movement for a load of $6 \mathrm{~N}$ (figure 17) shows the efficiency of this control method where the actual position of the machine follows the command value without oscillation and without error.

The major advantage of this technique of control is that can use for a classical stepper displacement (fig.15) and linear displacement (fig.17) for only changing the type of position reference.

To have a constant flow it is important to motorizing the pump-syringe with a linear and continuous displacement of the mover that can be obtained by the proposed control.

The use of the correction technique studied in section (IV.1) has allowed us to have a force developed by the actuator oscillating around its reference without using force sensors.

\section{CONCLUSION}

In this paper, we presented a control of linear switched reluctance motor for biomedical application (syringe-pump). A mathematical model of an LSRM neglecting magnetic saturation is performed. This model is used to study the open loop and closed-loop controllers using classical PID regulator and hysteresis controller. 
The first part of the paper is devoted to smooth the positioning of the actuator in open loop method namely BangBang method and positioning error correction with load.

The proposed architecture of the control strategy presented in the second part is a simple and optimized architecture based on the use of conventional PID controllers and hysteretic regulators without using a force sensor.

This control technique is very reliable in the case of the syringe pump application because it allowed having a constant and adjustable flow.

\section{References}

[1] T. R. Fredriksen, "Application of the Closed-Loop Stepping Motor," IEEE Trans. on Automatic Control, vol. AC-13, pp. 464-474, Oct. 1968.

[2] B. C. Kuo, "Closed-Loop and Speed Control of Step Motors," The 3rdAnnual Symposium Incremental Motion Control Systems and Devices, Urbana-Champaign, IL, May6-8, 1974.

[3] Ghislain REMY," Commande optimisée d'un actionneur linéaire synchrone pour un axe de positionnement rapide" Thèse de Docteur, Ecole doctorale $\mathrm{n}^{\circ} 432$ : Sciences des Métiers de l'Ingénieur,2007.

[4] Jufer M. " Electromécanique", Presses Polytechniques.Universitaires Romandes, Lausanne.,1995.

[5] Nicoud J.D. "Robots mobiles miniature", Techniques de l'Ingénieur, Traité Informatique Industrielle, 1995, R7760, pp. 1-12

[6] FAVRE.E, BRUNNER.D, PRAGET.C. "Principes et applications des moteurs linéaires", Revue d'automatisme, $\mathrm{N}^{\circ} 9$. Mars 2000.

[7] MAHMOUD Imed, "Design and modelling of a linear switched reluctance actuator for biomedical applications", International Journal of the Physical Sciences Vol. 6(22), pp. 5171-5180, 2 October, 2011.

[8] Boujemaa BS. "On the regulation of the syringes pump infusion controlled by stepper motor". International conference on electronic engineering. Oran: pp. 196-202,1994.

[9] Ben saad Kamel. "Modélisation et commande d'un moteur pas à pas tubulaire à reluctance réluctance variable et à quatres phases Approches conventionnelles, par logique floue, et par réseaux de neurones artificiels". Thèse de doctorat ,ENIT,1997

[10] Khidiri J. "Alimentation et commande d'un actionnaire linéaire triphasé à flux transversale " Thèse de Docteur Ingénieur, Université des Science et Technique de Lille FlandresArtois, 1986.

[11] KANT M. "Les actionneurs électriques pas à pas", Edition Hermès, 1989, Paris.

[12] Chi HP."Simplified flux-linkage model for switched-reluctance motors". IEE Proc. Electr. Power Appl. 152(3),2005.

[13] Ahmed K ."A Fourier Series Generalized Geometry-Based Analytical Model of Switched Reluctance Machines". IEEE transactions on industry application. 43(3).2007

[14] ACARNLEY P. "Stepping motors a guide to theory and practice", The Institution of Electrical Engineers, Edition IEE, London 2002.

[15] F R. SALMASI, R. B. SEPE, "Virtual Auto-Tuning Position and Torque Sensors for Switched Reluctance Motor Drives", IEEE Transactions on Industry Applications, pp. 1355-1361, 2004. 